\title{
Utilization of a Novel Distributed Energy System Based on Process Industry in Coking Production
}

\author{
Zhigang Tang, Hongwei Li, Zhimin He, Zhijun Zhao, and Dong Guo
}

\begin{abstract}
In order to solve problems of high operating cost troubled the domestic coking enterprises, this article presents a novel distributed energy system based on process industry (DESP). Through the establishment of Coke Oven-DESP (CO-DESP) and Tube Furnace-DESP (TF-DESP), replace the original energy flow network mainly using the steam and thermal conductive oil with the new energy flow network mainly using flue gas and hot un-loaded wash oil. Amount of waste heat recovered during process by CO-DESP and TF-DESP is $16 \mathrm{Mkcal} / \mathrm{h}$ and $5.1 \mathrm{Mkcal} / \mathrm{h}$, respectively. It effectively reduces the running costs of coking process and greatly increases the competitiveness of domestic coking enterprises.
\end{abstract}

Index Terms-Coking, distributed energy system, flue gas, hot lean oil.

\section{INTRODUCTION}

Started from coke output of 525 thousand ton per year in 1949, China coking industry increased greatly. In 1994, coke output had reached 1.15 billion tons per year. Only after 10 years, coke output had break 2 billion tons per year. Now in 2013, as shown in Fig. 1, coke output climbed a new record of 4.42 billion tons per year and occupied $67.63 \%$ of world coke output. China coking industry experienced a "glorious decade" development and becomes one of "eight major industries" with output value exceeding a trillion [1], [2].

But in these years, some unsustainable developing patterns, such as excessive pursuing scale expansion and extensive management, are always troubled China coking industry. It has to face more and more press of rising production cost, heavy market press, homogenized competition. The living space of domestic coking enterprise is severely compressed narrowly and narrowly.

Recapping progress in China coking process during the latest 10 years, emerged a series of new technologies, such as large scale coke oven technology, tamping coking oven technology, coke cooling dry quenching technology (CDQ), coal moisture control technology $(\mathrm{CMC})$, vacuum distillation technology, coal blending optimization technology, preparation of methanol by COG technology, hydrogenation of coking products technology, etc, has effectively improve the coking products structure, low down the coking operating cost and increase the cleanliness of coking production, to some extends. But according to the factual operating performance there is still lot of problems, such as: (1) High

Manuscript received January 20, 2015; revised March 20, 2015.

Zhgang Tang, Hongwei Li, Zhimin He, Zhijun Zhao, and Dong Guo are with the State Key Laboratory of Chemical Engineering, Chemical Engineering Department, Tsinghua University, Beijing 100084 China (e-mail: zhg-tang@mail.tsinghua.edu.cn, lihw12@qq.com, thaaam@yeah.net, zhaozj@mail.tsinghua.edu.cn, studing@sina.com). process energy consumption. Now days the average process energy consumption of domestic coking process is $124 \mathrm{kgce} / \mathrm{t}$ coke, is heavily high than that the theoretic value of coking production $69.6 \mathrm{kgce} / \mathrm{t}$ coke; (2) Poor recovery of secondary energy. Most of the domestic coking enterprises generally lacks of effectively recovery of secondary energy. Even considering implement of CDQ developed in recent years, the recovery yield of secondary energy is only $26.5 \%$.

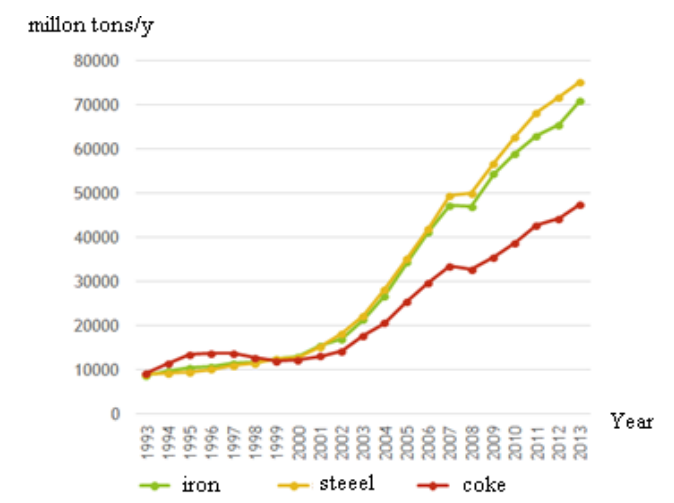

Fig. 1. Development of China coking output during 1993-2013.

If we make an estimation based on average value of coking process energy consumption value $122 \mathrm{kgce} / \mathrm{t}$ in 2013 , according to the total output of coke in China is 4.43 billion tons, it almost consumes 0.54 billion tons ce and emits 1.33 billion ton $\mathrm{CO}_{2}$. Especially, large amount of secondary energy carried with the flue gas, equivalent of 0.10 billion tons ce, carried with the crude oven gas, equivalent of 0.17 billion tons ce, almost lost without any re-utilization [3], [4].

In summary, lack of effectively recovery of secondary energy in process is the main reason leading to high operating cost of coking industry. Even a number of new technology have been promoted in recent years, but it is lack of comprehensively and systematically analysis in secondary recovery, especially lack of considering matching between quality and quantity and coupling with space and time in re-using of secondary energy, the expected energy-saving effects hardly can be achieved. In the view of the above, in this paper, under the guidance of basic theories of process science, according to the principles of systematic planning and global optimization, a novel distributed energy system based on coking process (DESP) was presented. Further, a DESP with coke oven as the center (CO-DESP) and a DESP with tube furnace as the centre (TF-DESP) was established respectively. In these two DESPs, heat of hot coke, COG and flue gas is re-utilized in multi-stage and multi-effective patterns, the energy flow network is re-constructed and optimized. By application of these measures, the energy efficiency has improved greatly and operating cost has dropped significantly. 


\section{METHODS}

\section{A. Distributed Energy System Based on Process}

Distributed energy system (DES) is quietly different from the conventional Concentrated Energy System (CES). This system is actually one of integrated multi-production system, based on concept of energy cascade utilization, which can make use of waste heat exhausted from thermal equipment to produce steam or fuel gas, driving generator or fuel cell to supply electricity. It also can make use of waste heat exhausted from thermal equipment to supply civilian heating in the winter while supply civilian cooing by adoption of absorption heat pump.

DES was firstly proposed in the late $19^{\text {th }}$ century by Britain, the United States, Canadian, etc. At the time, most of these countries suffered blackouts, scientist have begun to doubt the traditional system of production and supply of electricity. Taking account of long construction period, high equipment investment, expensive transmission cost and un-steady option reliability of conventional large-scale power plants, distributed power system (DPS) is presented firstly presented and promoted in the United States and accepted by the other countries [5], [6].

This so-called DPS refers one kind of small-scale power unit near the final users, with the capacity of $1 \mathrm{kw} \sim 5 \mathrm{kw}$, can be operated integrated or alone. It is always combined with manage and storage of energy to improve the energy efficiency of electricity supply. This system is commonly built in areas not suitable for construction centralization power station, such as the industrial park, building, community zones, etc, or near the end of transmission grid. Compared with the large-scale and centralized power system, it can effectively reduce investment for long-distance electricity transmission and energy losses during long-distance transmission, supply clean energy with higher reliability.

DPS is quietly different from the past conception of "small size power unit". Compared with the conventional power system, it is characterized by: (1) save transmission investment; (2) enhance the reliability of power supply; (3) is one of important supplementary means to the main transmission grid meeting some special needs; (4) has good environmental performance; (5) have feature of cascade utilization and high energy efficiency up to $90 \%$;(6) open up a new avenues for making use of renewable energy [7], [8].

DESP extended and developed on the basis of DPS has the biggest bright spot as converting and supplying energy nearby users. It has advantages of providing solutions to personalized users with variety of energy supply. According to theory of DESP, if a DESP is established with taking full advantage of waste energy, it will achieve tremendous economic and energy-saving effects.

\section{B. Construction and Characteristics of Coking-DESP}

This paper put forwards the conception of coking-DESP, in which the waste energy is made fully utilization and the energy flow network is optimized in order to improve the overall energy efficiency of coking process. It is characterized in that: take the primary energy user coke oven or tube furnace as the centre, make use of secondary heat released from them to form DESP near the local users.

DESP based on coke oven (CO-DESP), for example, is come into being by using the waste heat of hot coke, flue gas and raw COG to serve the users with the coking process, as shown in Fig. 2. Waste heat of hot coke with temperature $950 \sim 1050^{\circ} \mathrm{C}$ can be used to generate electricity power by CDQ. For a coking plant with annual output of 1 million tons, it will recovery power generation $1.625 \times 10^{8} \mathrm{MWh}$, not only fully meets the internal demand of electricity in coking process, but also has surplus power can be exported output.

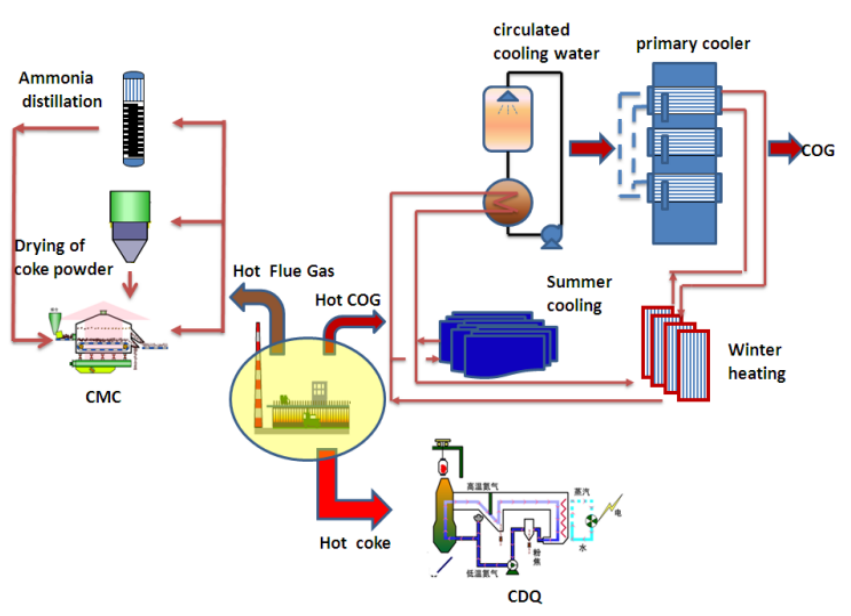

Fig. 2. The sketch map of CO-DESP

Waste heat of flue gas exhausted from coke oven with temperature about $250^{\circ} \mathrm{C}$ can be used in ammonia-distillation of phenolic effluent, drying of coke powder and CMC of charred coal. Ammonia-distillation by flue gas heat can replace the classical heating-medium steam or thermal oil and save the primary energy sources. Coke power after dried by flue gas heat can be recycled in coal blending as coking material to improve the production of coke. Flue gas heat used in CMC can reduce the water content of coal feedstock and cut down the consumption of coke oven heating.

In all the waste heat from coke oven with a potential to be recovered, except for hot coke heat (accounting for 37.13\%) and flue gas heat (accounting for $17.11 \%$ ), raw COG still has considerable recovery value (accounting for $34.31 \%$ ). Since it has technical difficulty in heat recovery during high-temperature zone $\left(800 \sim 150^{\circ} \mathrm{C}\right)$, heat recovery of COG in concentrated in the low-temperature region, such as to make use of heat of circulated cooling water in gas uptakes and the heat of upper section in primary cooler of COG, for winter heating and summer cooling.

Due to it is fully considered the situ-recovery and situ-utilization, the match of space and time and, the match of quantity and quality, CO-DESP greatly improves the self-consistency and achieve the obvious energy-saving effects.

Similarly, the sketch map of DESP based on tube furnace (TF-DESP) in coking process is shown in Fig. 3. Tube furnace provides the heat of de-benzolization tower for de-benzene from loaded wash oil, while exhaust the flue gas $\left(250 \sim 300^{\circ} \mathrm{C}\right)$ and unloaded wash oil stream $\left(\left(220 \sim 240^{\circ} \mathrm{C}\right)\right.$, with the potential of recovery. Thus a TF-DESP will be formed, in which flue gas of tube furnace can be used as the heating source for drying of ammonia sulfate replacing the steam. In order to achieve the best results, hot un-loaded wash oil can be used cascade in the turns of heating feedstock of debenzolization tower, heating of desulfurization solution, 
heating of COG into saturator, holding of oil depot temperature.

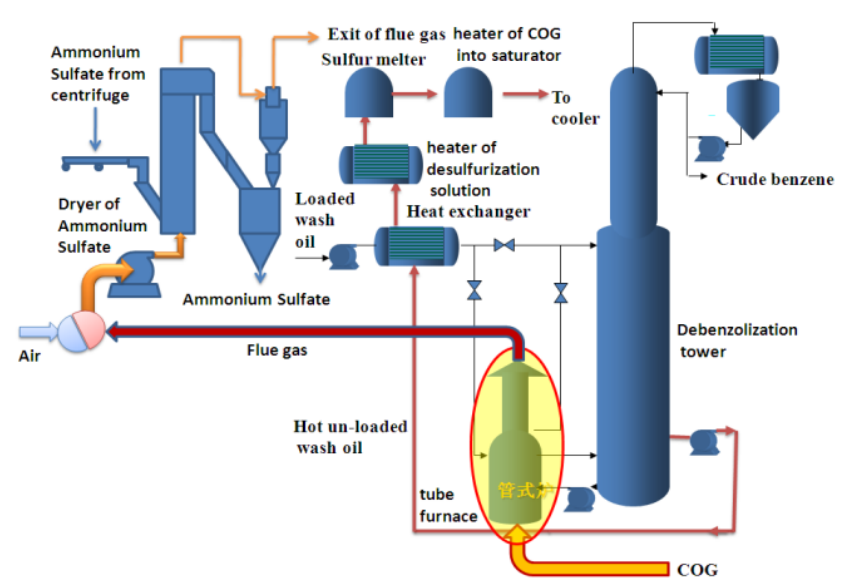

Fig. 3. The sketch map of TF-DESP.

\section{RESUlTS AND DISCUSSION}

As described in Section II.B the key of DESP is recovery in situ and re-using of heat of process stream in situ. These streams actually undertake the conventional heating utilities. A novel energy flow network composed by these streams replaces the conventional energy flow network composed by steam and thermal oil.

\section{A. Canceling of the Conventional Energy Flow Network}

With an annual output of 1.3 million tons coke plant, for example, the original energy networks is mainly consist of steam and thermal oil. In summer, consumption of steam is about $25 \mathrm{t} / \mathrm{h}$, equivalent to $15 \mathrm{Mckal} / \mathrm{h}$, which is mainly used in lithium bromide absorption refrigerating, heating of debenzolization tower, preserving heat of electrical tar precipitator, heating of $\mathrm{COG}$ into saturator, heating of desulfurization solution, dehydrating of tar depot and insulation works, etc. Because the steam is bled from the CDQ power unit, using of lot of steam is equivalent to the loss of electricity generation with 9 million kwh per year. In winter, consumption of steam is about $10 \mathrm{t} / \mathrm{h}$, equivalent to 6 $\mathrm{Mckal} / \mathrm{h}$. Except for refrigeration unit, the other users is as the same as in summer. It also will lead to loss of power with 3.6 million kwh per year. The existing thermal oil system is heated by COG. The consumption of COG is about 1300 $\mathrm{NM}^{3} / \mathrm{h}$ per, equivalent to $5.6 \mathrm{Mckal} / \mathrm{h}$. The main users of thermal oil are re-boiler of ammonia distillation tower, pre-heater of air in ammonium sulfate dryer and sulfur melter.

If DESP as shown in Section II.B is adopted, it can almost replace the original energy flow network based on steam and thermal oil, build a new energy network mainly based on flue gas and hot process stream.

\section{B. Constructing the New Energy System Mainly Based on Flue Gas and Hot Process Stream}

Originally, except for apparent heat of coke oven flue gas between $230^{\circ} \mathrm{C}$ and $800^{\circ} \mathrm{C}$ is used to heat coke oven regenerator, apparent heat below $230^{\circ} \mathrm{C}$ is almost lost. Flue gas of tube furnace is only used for pre-heating of loaded wash oil, the other apparent heat is also fundamentally lost, as shown in Fig. 4.

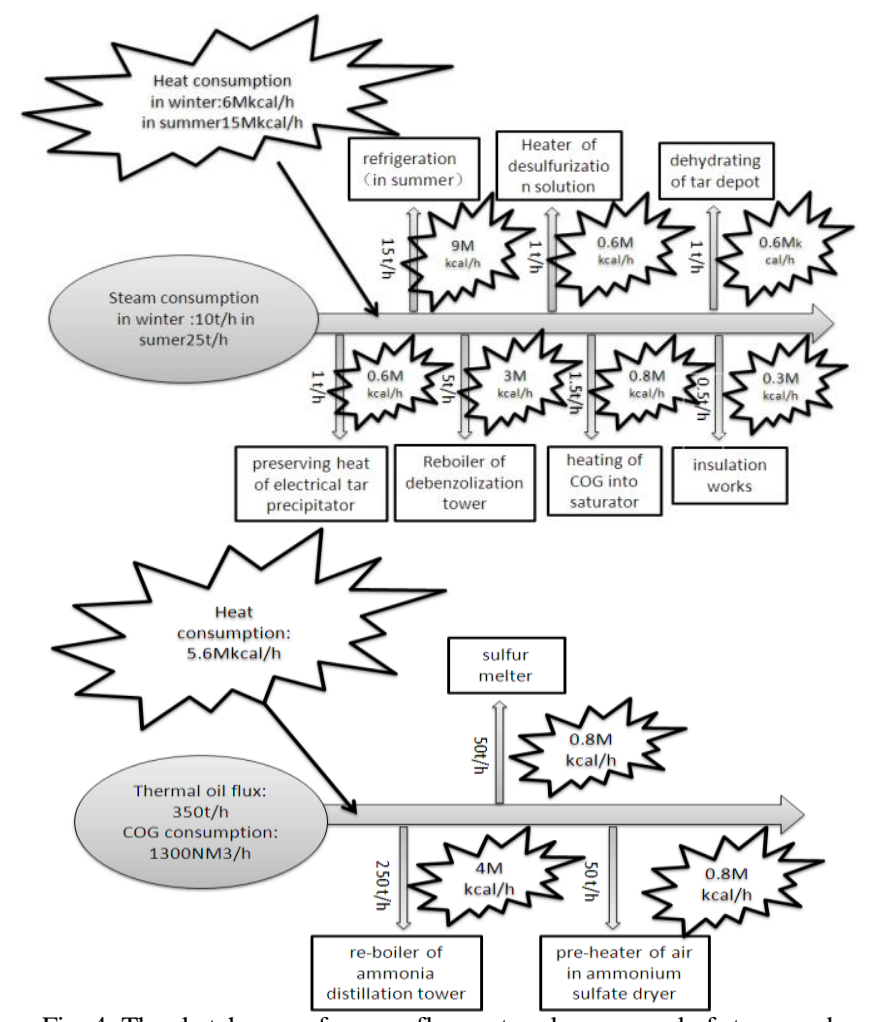

Fig. 4. The sketch map of energy flow network composed of steam and thermal oil.

CO-DESP newly constructed re-plans the configuration of coke oven flue gas, which is used as the heating source of ammonia distillation, coke power drying and CMC, as shown in Fig. 5. By re-building energy flow network of coke oven flue gas, re-optimization of utilization of coke oven flue gas will recovers flue gas heat about $16 \mathrm{Mkcal} / \mathrm{h}$.

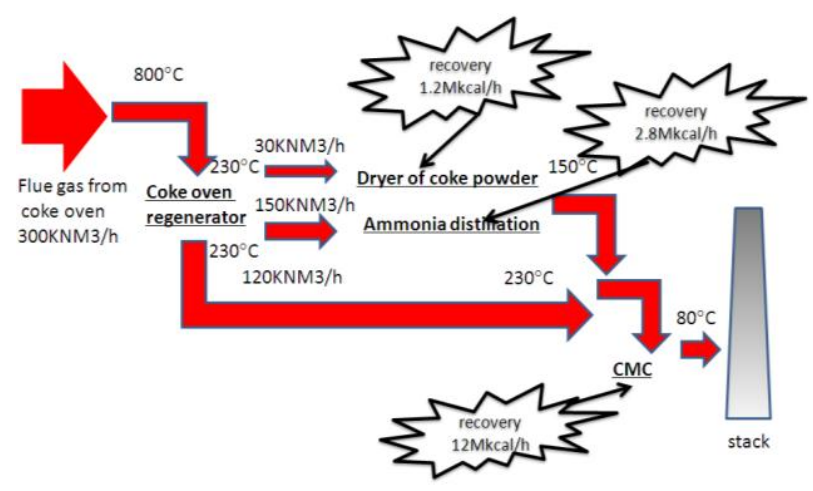

Fig. 5. The sketch map of energy flow network based on coke oven flue gas.

TF-DESP newly constructed re-optimizes the network of tube furnace oven flue gas, which is used as the heating source of ammonium sulfate drying, that is heating air into ammonium sulfate dryer, as shown in Fig. 6. Thus it can recover apparent heat about $0.4 \mathrm{Mkcal} / \mathrm{h}$.

Traditionally, hot un-loaded wash oil is just used for heating of loaded wash oil by heat exchanger, the other apparent heat is almost lost, as shown in Fig. 4. At the same time of building TF-DESP, this paper re-optimizes the configuration of hot un-loaded washing oil network. Now, the remaining apparent heat of un-loaded washing oil is used for heating of COG into saturator, heating of sulfur melter and concentrator of desulfurization waste solution, respectively, as shown in Fig. 7. It can recover heat about 4.7 $\mathrm{Mkal} / \mathrm{h}$. 


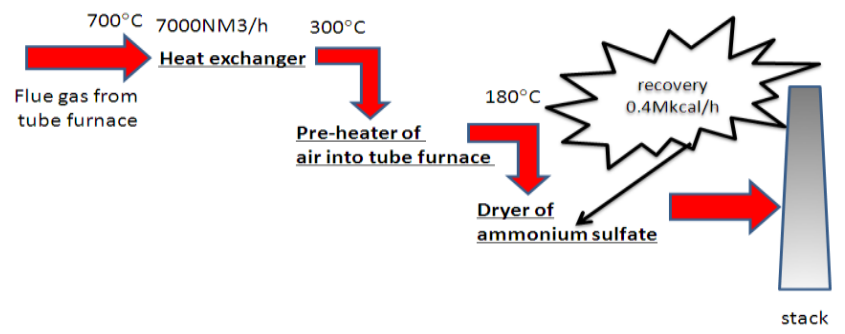

Fig. 6. The sketch map of energy flow network based on tube furnace flue gas.

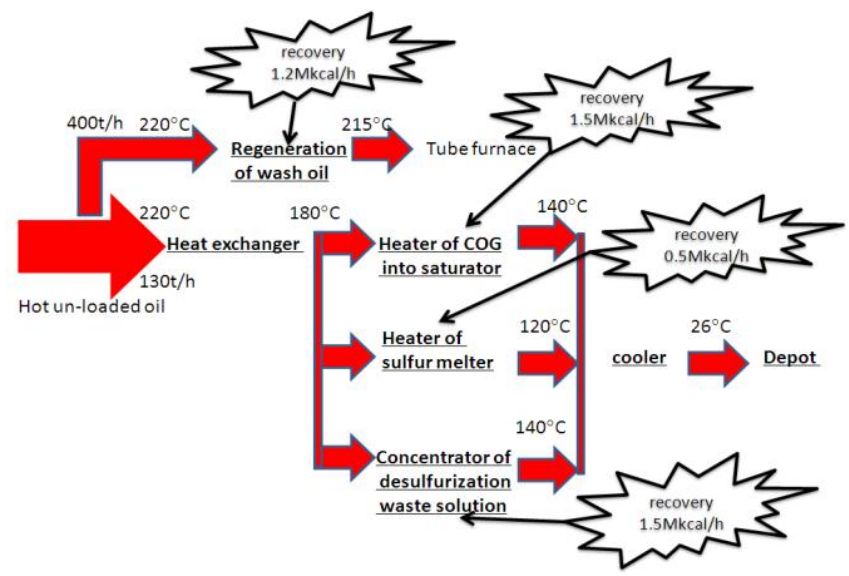

Fig. 7. The sketch map of energy flow network based on un-loaded wash oil.

\section{CONCLUSION}

For a coking plant with annual output 1 million tons per year, CO-DESP can recovers process secondary energy $1.35 \times 10^{6} \mathrm{GJ} / \mathrm{Y}$, equivalent to standard coal 46,250 tons per year; TF-DESP can recovers process secondary energy $0.187 \times 10^{6} \mathrm{GJ} / \mathrm{Y}$, equivalent to standard coal 6,380 tons per year. In view of obvious energy-saving effects, DESP is effective measure to reduce the cost of coking process.

DESP based on coking process and re-construction of energy flow network makes full use of secondary energy in coking process, by systematic designing, coupling match, multiple-effectively recovery and multiple-orderly utilization, effectively cuts down the production cost, greatly improves competitiveness of coking enterprise.

DESP based on process presented in this paper has seldom been reported in literature. In view of excellent energy-saving performance, it has great potential for popularization. However, because the conception and theory of DESP is new, the current construction method mainly relies on empirical algorithm. In the further study, should deepen in research on methodology and mathematical model. On the basis of combing systematology, optimization theory and energy analytical science, form the basic principles for construction, optimization, modeling and algorithms, make great contribution to energy-saving in industrial process.

\section{REFERENCES}

[1] C. P. Jiang, "China's coking industry in 2013 and 2014 situation analysis review," World Metal News, p. A10, 2014

[2] H. Y. Ting, "Review and suggestion on development of China coking industry," Coal Processing and Comprehensive Utilization, no. 4, pp. $18-21,2014$

[3] H. C. Qing, Z. C. Xia, Z. X. Xiao, Q. Y. Hong, and Y. R. Yu, "Material and energy flow analysis of coking process in integrated steel plants," Journal of Iron and Steel Research, vol. 19, no. 6, pp. 16-20, 2007.
[4] F. H. Fu, "Huge energy-saving space in China coking industry," Chinese Metallurgy Newspaper, p. C01, June 2012.

[5] H. Ben, "Looking at distributed energy system from a strategic perspective: A solution to China low carbon development strategy for next 20 years,” Sino-Global Energy, vol. 61, pp. 21-27, 2010.

[6] W. W. Tao and L. Y. Hua, " Distributed system-China sustainable energy way," Economic Aspects, no. 5, pp. 21-24, 2014.

[7] Z. S. Ming, "Promote distributed energy sources system vigorously," Journal of Shenyang Institute of Engineering (Natural Science), vol. 10, no. 2, pp. 97-101, 2014.

[8] J. H. Qin, "Development and policy analysis of U.S. distributed energy system," Science and Technology Research, no. 12, pp. 19-22, 2014.

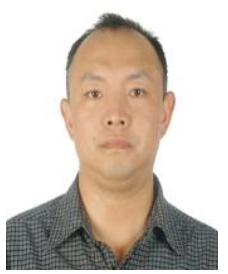

Zhigang Tang was born in Lanzhou City, Gansu Province, China, on April 1, 1970. He got his bachelor degree from the Chemical Engineering Department, Tsinghua University, Beijing, in June 1993. He got his Ph.D. degree from the Chemical Engineering Department, Tsinghua University, Beijing, in April 1998.

In 1998, he was hired as a lecturer of the Chemical Engineering Department, Tsinghua University, Beijing. In 2000 (to now), he was hired as an associate professor of the State Key Laboratory of Chemical Engineering, Chemical Engineering Department, Tsinghua University, Beijing. He teaches two graduate-oriented courses: "Fundamental in separation process" and "Generality of low-carbon process". His current research interests include fundamental and application of identified methods in vapor-liquid mass transfer, process and equipment in clear and low-carbon industrial production, trapping $\mathrm{CO}_{2}$ from syngas by hybrid technology.

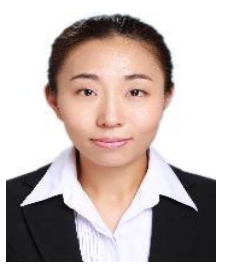

Hongwei Li was born in Dezhou City, Shandong Province, China, on May 5, 1989. She got her bachelor degree from the Department of Environmental Engineering, North China Institute of Science and Technology, Hebei, in June 2012. She is a third year master student at the Chemical Engineering Department, Tsinghua University, Beijing. Her paper project is $\mathrm{CO}_{2}$ absorption by physical solvent and $\mathrm{CO}_{2}$ capture from syngas bycryogenic distillation.

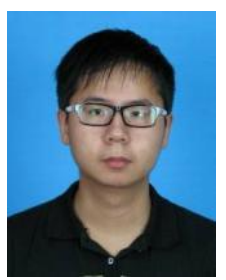

Zhimin He was born in Yiyang, Hunan Province, Chinese in October 7, 1991, he got his bachelor's degree in August 2014, from the Department of Chemical Engineering, Tsinghua University, Beijing. His current research interests include how to make the membrane with high-throughput and high-enriched factor, and clear, low carbon industrial production process.

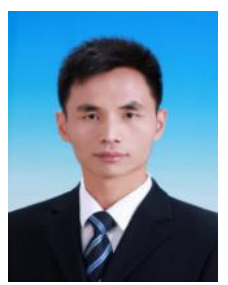

Zhijun Zhao was born in Shijiazhuang City, Hebei Province, China, on October 28, 1980. He got his master degree from the Department of Chemical Engineering, Tianjin University, Tianjin, in June 2008. From September 2014, he has been a post-doctor of the Department of Chemical Engineering, Tsinghua University, Beijing. His current research interests include molecular simulations and properties, preparation and application of ionic liquids, capturing acid gases $\left(\mathrm{CO}_{2}, \mathrm{H}_{2} \mathrm{~S}\right.$ and $\left.\mathrm{SO}_{2}\right)$ from flue gas or syngas by green solvent.

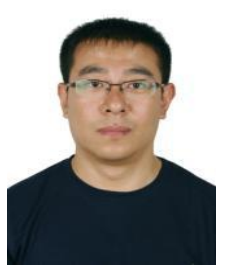

Dong Guo was born in Jinzhong Shanxi Province, China on May 25, 1978. From August 2010 till now, he has been working as a research assistant of the Department of Chemical Engineering, Tsinghua University, Beijing. His current research interests include principle and the application in the identification method of gas liquid mass transfer, clear, low carbon industrial production process and equipment. 